RESEARCH BRIEF

\title{
Association Between the Tips From Former Smokers Campaign and Smoking Cessation Among Adults, United States, 2012-2018
}

\author{
Rebecca Murphy-Hoefer, PhD, MPH ${ }^{1}$; Kevin C. Davis, $\mathrm{MA}^{2}$; Brian A. King, PhD, $\mathrm{MPH}^{1}$; \\ Diane Beistle, $\mathrm{BA}^{1}$; Robert Rodes, MS, MBA ${ }^{1}$; Corinne Graffunder, DrPH, $\mathrm{MPH}^{1}$
}

\begin{abstract}
Accessible Version: www.cdc.gov/pcd/issues/2020/20_0052.htm
Suggested citation for this article: Murphy-Hoefer R, Davis KC, King BA, Beistle D, Rodes R, Graffunder C. Association Between the Tips From Former Smokers Campaign and Smoking Cessation Among Adults, United States, 2012-2018. Prev Chronic Dis 2020; 17:200052. DOI: https://doi.org/10.5888/pcd17.200052.
\end{abstract}

\section{PEER REVIEWED}

\section{Summary}

What is already known on this topic?

The Centers for Disease Control and Prevention's Tips From Former Smokers (Tips) campaign is associated with increased quit attempts among specific populations of people who smoke, including African Americans, pregnant women, people with mental health conditions, and those with lower educational attainment. The campaign increases calls to smoker quitlines and visits to the Tips website and other cessation resources.

\section{What is added by this report?}

During 2012-2018, the Tips campaign was associated with an estimated 16.4 million quit attempts and more than 1 million sustained quits among US adults.

What are the implications for public health practice?

Mass media campaigns, such as the Tips campaign, can increase smoking quit attempts and sustained quits as part of a comprehensive approach to reducing smoking-related disease and premature death in the United States.

\section{Abstract}

In 2012, the Centers for Disease Control and Prevention (CDC) launched the national Tips From Former Smokers (Tips) campaign to encourage people who smoke to quit by showing real-life heath consequences of tobacco use and promoting evidence-based resources for quitting. To assess the campaign's impact on quit attempts and sustained-quit estimates (ie, quits lasting $\geq 6 \mathrm{mos}$ ),
CDC analyzed data from a nationally representative longitudinal survey of US adults who smoke cigarettes, aged 18 years or older in 2012-2018. The Tips campaign was associated with an estimated 16.4 million quit attempts and 1,005,419 sustained quits. Continued implementation of cessation campaigns, including the Tips campaign, could accelerate progress toward reducing rates of smoking-related diseases and death.

\section{Objective}

Cigarette smoking remains the leading cause of preventable death in the United States (1). For every person who dies because of cigarette smoking, at least 30 people live with a serious smokingrelated illness (1). Evidence-based media campaigns can increase tobacco cessation, increase use of cessation resources such as quitlines, and change tobacco-related social norms $(2,3)$. This study aimed to determine the 7-year impact of the Tips From Former Smokers (Tips) campaign on population-level smoking cessation by measuring cumulative campaign-associated quit attempts and sustained quit estimates, accounting for smoking relapse.

\section{Methods}

The Centers for Disease Control and Prevention (CDC) collected data from the KnowledgePanel (www.knpanel.com) (KP), an ongoing national online survey of adults in the United States. KP recruitment is conducted through random sampling of US household mailing addresses, and respondents are followed over time, allowing for participation in multiple survey waves. Current cigarette smokers are defined as people who smoked at least 100 cigarettes in their lifetime and who smoked every day or some days at the time of survey. We included data from the 2012-2018 waves of this survey $(\mathrm{N}=35,275$ observations on 9,653 unique current smokers) to assess the impact of Tips campaign exposure on quit attempts and sustained quit estimates. 
We used a geography-based quasi-experimental design that relates variation in Tips campaign exposure across media markets and time to individual quit attempt behaviors across time. Quit attempts in the past 3 months among current cigarette smokers were assessed by asking, "During the past 3 months, how many times have you stopped smoking for 1 day or longer because you were trying to quit smoking cigarettes for good?" We created an indicator variable for having made at least 1 quit attempt in the past 3 months. Tips campaign exposure was determined by calculating past 3-month cumulative campaign television gross ratings points (GRPs, a measure of market-level campaign dose) and merging them with individual survey responses based on respondents' media market of residence and survey date. We used logistic regression to relate self-reported quit attempts in the past 3 months to GRPs (3). The model controlled for age, sex, race/ethnicity, education level, annual household income, presence of chronic physical or mental health conditions, tobacco surveys taken in the past year, presence of children in the household, presence of others who smoke cigarettes in the household, cigarette smoking prevalence in the respondent's television market, state fixed effects, and a linear time trend to control for secular trends over time. Model results were used to estimate the predicted quit attempt rate differential between observed doses of zero GRPs (ie, no campaign) and the average quarterly Tips campaign dose of 1,200 GRPs from 2012 to 2018 (ie, matching CDC recommendations on GRP dose) (2). The quit attempt rate differential was then multiplied by the yearly adult smoker population to create an initial estimate of total campaign-attributable quit attempts for each year during 2012-2018. Finally, the year-specific projections of campaignattributable quit attempts were adjusted to account for the number of quarters the campaign was on the air in each year.

Sustained quit estimates were calculated using the estimated proportion of campaign-attributable quit attempters who remained abstinent from smoking at 6-month follow-up. On the basis of survey timing and resources, we were able to estimate sustained quitting during 4 of the 7 years of data in the analysis. Sustained quit rates averaged $7.2 \%$ in the available data. Because our sample was not designed to measure longer-term relapse, we used literaturebased estimates $(4,5)$ to calculate approximate relapse $(15.3 \%)$ for 1 year after the initial 6 months of cigarette abstinence.

\section{Results}

The Tips campaign was correlated with increased odds of a quit attempt in the past 3 months (odds ratio $=1.19 ; 95 \%$ confidence interval [CI], 1.11-1.27) (Table 1). An average of 1,200 GRPs per quarter translated into a $3.9(95 \%$ CI, 3.4-4.3) percentage point increase in quit attempts per quarter during 2012-2018. Past 3month quit attempt rates ranged from $32.5 \%$ in the absence of the campaign (0 GRPs) to $39.7 \%$ (4,000 GRPs) during the 2012-2018 campaigns (4,000 GRPs). Approximately 16.4 million quit attempts and an estimated 1,005,419 sustained quits lasting at least 1 year $(95 \%$ CI, 876,519-1,108,539) were associated with Tips during 2012-2018 (Table 2). Sustained quit estimates ranged from 103,729 in 2012 to 188,577 in 2017.

\section{Discussion}

During 2012-2018, the Tips campaign contributed to 16.4 million quit attempts and more than 1 million estimated sustained quits. These results are consistent with previous evaluations of the Tips campaign that have shown significant campaign effects on quit attempts and sustained quit estimates (eg, 1.6 million and 100,000 in 2012 (6); 1.83 million and 104,000 in 2014 (7); and 9 million and 522,000 in 2012-2015 (8), respectively). Additionally, the impact of Tips on quit attempts was recently supported with a study using data from the Behavioral Risk Factor Surveillance System (9).

Prior studies have also reported the impact of the Tips campaign on quit attempts among specific populations, including African Americans, pregnant women, people with mental health conditions, and those with less educational attainment (10). The campaign has also been associated with cessation-related outcomes, such as increased calls to 1-800-QUIT-NOW (6) and 1-855DEJELO-YA (a national portal that routes Spanish-speaking callers to Spanish-language services from callers' state quitlines) (11), and visits to the Tips campaign website and other cessation resources (10).

These findings are subject to at least 2 limitations. The analysis used an average campaign effect estimated from 2012 to 2018. Although this effect may vary across years, research does not indicate significant variation in campaign effects over time (3). Another limitation is that we measured only television exposure and not other campaign channels such as radio, digital media, or billboards. Therefore, the estimated campaign effects may be conservative if total campaign exposure was underestimated.

In summary, the Tips campaign led to an estimated 16.4 million quit attempts and more than 1 million estimated sustained quits during 2012-2018, demonstrating that public health campaigns can be effective when they are based on scientific evidence and are of sufficient intensity and duration (2).

\section{Acknowledgments}

This study was funded by CDC. No copyrighted material, surveys, instruments, or tools were used.

The opinions expressed by authors contributing to this journal do not necessarily reflect the opinions of the U.S. Department of Health and Human Services, the Public Health Service, the Centers for Disease Control and Prevention, or the authors' affiliated institutions. 


\section{Author Information}

Corresponding Author: Rebecca Murphy-Hoefer, PhD, MPH, Research, Evaluation and Technical Assistance Team, Health Communications Branch, Office on Smoking or Health, National Center for Chronic Disease Prevention and Health Promotion, Centers for Disease Control and Prevention, 4770 Buford Highway, NE, Atlanta, GA 30341. Telephone: 770-488-8964. Email: Rebecca.Murphy@cdc.hhs.gov.

Author Affiliations: ${ }^{1}$ Office on Smoking and Health, National Center for Chronic Disease Prevention and Health Promotion, Centers for Disease Control and Prevention, Atlanta, Georgia. ${ }^{2}$ Center for Health Policy Science and Tobacco Research, RTI International, Research Triangle Park, North Carolina.

\section{References}

1. US Department of Health and Human Services. The health consequences of smoking - 50 years of progress: a report of the Surgeon General. Atlanta (GA): US Department of Health and Human Services, Centers for Disease Control and Prevention, National Center for Chronic Disease Prevention and Health Promotion, Office on Smoking and Health; 2014.

2. Centers for Disease Control and Prevention. Best practices for comprehensive tobacco control programs - 2014. Atlanta (GA): US Department of Health and Human Services, Centers for Disease Control and Prevention, National Center for Chronic Disease Prevention and Health Promotion, Office on Smoking and Health; 2014.

3. Davis KC, Patel D, Shafer P, Duke J, Glover-Kudon R, Ridgeway W, et al. Association between media doses of the Tips From Former Smokers campaign and cessation behaviors and intentions to quit among cigarette smokers, 2012-2015. Health Educ Behav 2018;45(1):52-60.

4. Dai H, Leventhal AM. Association of electronic cigarette vaping and subsequent smoking relapse among former smokers. Drug Alcohol Depend 2019;199:10-7.

5. Herd N, Borland R, Hyland A. Predictors of smoking relapse by duration of abstinence: findings from the International Tobacco Control (ITC) Four Country Survey. Addiction 2009; 104(12):2088-99.

6. McAfee T, Davis KC, Alexander RL Jr, Pechacek TF, Bunnell R. Effect of the first federally funded US antismoking national media campaign. Lancet 2013;382(9909):2003-11.

7. Neff LJ, Patel D, Davis K, Ridgeway W, Shafer P, Cox S. Evaluation of the national Tips From Former Smokers campaign: the 2014 longitudinal cohort. Prev Chronic Dis 2016;13:150056.
8. Murphy-Hoefer R, Davis KC, Beistle D, King BA, Duke J, Rodes R, et al. Impact of the Tips From Former Smokers campaign on population-level smoking cessation, 2012-2015. Prev Chronic Dis 2018;15:180051.

9. Davis KC, Murphy-Hoefer R, Levine B, King BA, Hu S, Rodes R. Evidence of the impact of the Tips From Former Smokers Campaign: results From the Behavioral Risk Factor Surveillance System. Prev Chronic Dis 2019;16:190110.

10. Centers for Disease Control and Prevention. Tips impact and results. https://www.cdc.gov/tobacco/campaign/tips/about/ impact/campaign-impact-results.html. Accessed June 10, 2020.

11. Zhang L, Babb S, Johns M, Mann N, Thompson J, Shaikh A, et al. Impact of US antismoking TV ads on Spanish-language quitline calls. Am J Prev Med 2018;55(4):480-7.

The opinions expressed by authors contributing to this journal do not necessarily reflect the opinions of the U.S. Department of Health and Human Services, the Public Health Service, the Centers for Disease Control and Prevention, or the authors' affiliated institutions. 


\section{Tables}

Table 1. Association Between Making a Quit Attempt in the Past 3 Months and Select Characteristics, Tips From Former Smokers Campaign, United States, 2012-2018

\begin{tabular}{|c|c|}
\hline Model Covariate ${ }^{a}$ & OR $(95 \% \mathrm{Cl})$ \\
\hline Total campaign mass media market GRPs, past 3 months (square root functional form) & $1.19(1.11-1.27)$ \\
\hline Age & $0.98(0.98-0.99)$ \\
\hline \multicolumn{2}{|l|}{ Sex } \\
\hline Female & 1 [Reference] \\
\hline Male & $0.87(0.78-0.97)$ \\
\hline \multicolumn{2}{|l|}{ Race/ethnicity } \\
\hline White & 1 [Reference] \\
\hline Black & $1.55(1.29-1.86)$ \\
\hline Hispanic & $1.90(1.59-2.26)$ \\
\hline Other & $1.37(1.08-1.75)$ \\
\hline \multicolumn{2}{|l|}{ Education } \\
\hline Less than high school & 1 [Reference] \\
\hline High school diploma & $1.08(0.91-1.29)$ \\
\hline Some college & $1.28(1.08-1.52)$ \\
\hline Bachelor's degree or higher & $1.69(1.38-2.06)$ \\
\hline \multicolumn{2}{|l|}{ Annual household income, $\$$} \\
\hline$<20,000$ & 1 [Reference] \\
\hline $20,000-49,999$ & $0.88(0.78-1.00)$ \\
\hline $50,000-99,999$ & $0.97(0.84-1.12)$ \\
\hline$\geq 100,000$ & $0.80(0.67-0.97)$ \\
\hline Chronic condition & 1 [Reference] \\
\hline Physical & $1.27(1.14-1.42)$ \\
\hline Mental & $1.08(0.97-1.20)$ \\
\hline Tobacco surveys past year & $0.93(0.90-0.96)$ \\
\hline Child in household & $1.25(1.12-1.40)$ \\
\hline Smoker in household & $0.56(0.51-0.62)$ \\
\hline Smoking prevalence (mass media market level) & $0.99(0.96-1.02)$ \\
\hline Linear time & $0.997(0.99-1.00)$ \\
\hline No. of model observations & 35,275 \\
\hline
\end{tabular}

Abbreviations: $\mathrm{Cl}$, confidence interval; GRPs, gross rating points; OR, odds ratio.

${ }^{a}$ Model includes covariates for state fixed effects (not shown). 
Table 2. Estimated Campaign Cumulative Impact on Sustained Quits, Tips From Former Smokers Campaign, United States, 2012-2018

\begin{tabular}{|c|c|c|c|c|}
\hline Campaign Year & Dates On Air & $\begin{array}{l}\text { Number of Quarters } \\
\text { Campaign on Air }\end{array}$ & $\begin{array}{l}\text { Estimated Campaign- } \\
\text { Associated Quit Attempts } \\
(\mathrm{n}=16,440,928)\end{array}$ & $\begin{array}{l}\text { Estimated Campaign- } \\
\text { Associated Sustained } \\
\text { Quits }^{a}(n=1,005,419)\end{array}$ \\
\hline 2012 & March 19-June 19 & 1.00 & $1,696,214$ & 103,729 \\
\hline 2013 & March 4-June 17 & 1.16 & $1,964,772$ & 120,152 \\
\hline 2014 & February 3-April 6; July 7-September 7 & 1.50 & $2,436,389$ & 148,994 \\
\hline 2015 & March 30-August 16 & 1.49 & $2,198,523$ & 134,447 \\
\hline 2016 & January 25-June 12 & 1.53 & $2,385,108$ & 145,858 \\
\hline 2017 & January 9-July 30 & 2.22 & $3,083,677$ & 188,577 \\
\hline 2018 & April 23-October 14 & 1.92 & $2,676,245$ & 163,662 \\
\hline
\end{tabular}

${ }^{\mathrm{a}}$ Assuming a $15.3 \%$ relapse rate. 